\title{
Influence of psychological response on survival in breast cancer: a population-based cohort study
}

M Watson, J S Haviland, S Greer, J Davidson, J M Bliss

\begin{abstract}
Summary
Background The psychological response to breast cancer, such as a fighting spirit or an attitude of helplessness and hopelessness toward the disease, has been suggested as a prognostic factor with an influence on survival. We have investigated the effect of psychological response on disease outcome in a large cohort of women with early-stage breast cancer.
\end{abstract}

Methods 578 women with early-stage breast cancer were enrolled in a prospective survival study. Psychological response was measured by the mental adjustment to cancer (MAC) scale, the Courtauld emotional control (CEC) scale, and the hospital anxiety and depression (HAD) scale 4-12 weeks and 12 months after diagnosis. The women were followed up for at least 5 years. Cox's proportional-hazards regression was used to obtain the hazard ratios for the measures of psychological response, with adjustment for known clinical factors associated with survival.

Findings At 5 years, 395 women were alive and without relapse, 50 were alive with relapse, and 133 had died. There was a significantly increased risk of death from all causes by 5 years in women with a high score on the HAD scale category of depression (hazard ratio 3.59 [95\% $\mathrm{Cl} 1 \cdot 39-9 \cdot 24]$ ). There was a significantly increased risk of relapse or death at 5 years in women with high scores on the helplessness and hopelessness category of the MAC scale compared with those with a low score in this category (1.55 [1.07-2.25]). There were no significant results found for the category of "fighting spirit".

Interpretation For 5-year event-free survival a high helplessness/hopelessness score has a moderate but detrimental effect. A high score for depression is linked to a significantly reduced chance of survival; however, this result is based on a small number of patients and should be interpreted with caution.

Lancet 1999; 354: 1331-36

See Commentary page ???

Royal Marsden Hospital NHS Trust, Sutton and London (M Watson PhD); Institute of Cancer Research, Sutton (M Watson, J S Haviland MSc, J Davidson MSc, J M Bliss MSc); and St Raphael's Hospice, North Cheam, Surrey, UK (S Greer MD)

Correspondence to: Dr M Watson, Royal Marsden Hospital NHS Trust, Sutton, Surrey SM2 5PT, UK

(e-mail: maggie.watson@rmh.nthames.nhs.uk)

\section{Introduction}

There have been many suggestions of a role for psychological response in the outcome of cancer, but little scientific evidence. A few studies examined the influence of psychiatric symptoms on disease outcome in patients with breast cancer. The presence of psychiatric symptoms, including emotional distress, was significantly related to poorer prognosis in two studies, ${ }^{1,2}$ whereas three found no relation between psychiatric symptoms and disease outcome. ${ }^{3-5}$ These studies were limited by their small sample size (most had fewer than 200 patients) or short period of follow-up, so reliable assessment of the effect of psychological response in women with early-stage breast cancer is difficult.

A few studies suggested that women who develop breast cancer may be more likely than those who do not to suppress negative emotion $6^{6-8}-$ the type $C$ personality. Subsequent research suggested a cancer-prone personality type characterised by abnormal inhibition of emotions and inability to express anger. ${ }^{9}$ D espite flimsy evidence for the cancer-prone personality, this research has been enthusiastically received by the lay press and by practitioners of alternative therapies. This psychological response has been implicated as a factor that may influence the development of cancer, but whether it is also associated with survival is not known. In one of the earliest prospective studies of psychological response and survival in breast cancer, Greer and colleagues found a significant link between prognosis and psychological response. ${ }^{10}$ Patients whose psychological responses were categorised as fighting spirit or denial were significantly more likely to be alive and relapse-free 5 years after diagnosis of an early-stage breast cancer than those whose response was of helplessness or stoic acceptance. These results were still significant at the 10-year follow-up. ${ }^{11}$ Nevertheless, this early study has several shortcomings: there were only 57 patients and there was no adjustment for the important prognostic variable of lymph-node status, because few data on node status were available at the beginning of the study. Furthermore, the original assessment of psychological response was restricted to a brief open-ended question rather than a more detailed and psychometrically reliable measure.

Our study aimed to replicate these findings in a large cohort, with a prevalidated assessment of psychological response, and control for all known prognostic factors. In addition, we investigated whether there were any associations between the individual dimensions of the mental adjustment to cancer (MAC) scale and overall or event-free survival, and similarly for the Courtauld emotional control (CEC) scale. Women were followed up for a minimum of 5 years. 


\begin{tabular}{|c|c|}
\hline Characteristic & Number of patients \\
\hline $\begin{array}{l}\text { Age (years) } \\
<50 \\
50-59 \\
60-69 \\
\geqslant 70\end{array}$ & $\begin{array}{c}172(29 \cdot 8 \%) \\
187(32 \cdot 4 \%) \\
185(32 \cdot 0 \%) \\
34(5.9 \%)\end{array}$ \\
\hline $\begin{array}{l}\text { Menopausal status } \\
\text { Premenopausal } \\
\text { Perimenopausal } \\
\text { Postmenopausal } \\
\text { Unknown }\end{array}$ & $\begin{aligned} 156 & (27 \cdot 0 \%) \\
38 & (6 \cdot 6 \%) \\
369 & (63 \cdot 8 \%) \\
15 & (2 \cdot 6 \%)\end{aligned}$ \\
\hline $\begin{array}{l}\text { WHO performance status rating } \\
\text { Grade } 0 \\
\text { Grade } 1 \\
\text { Grade } 2 \\
\text { Grade } 3 \\
\text { Unknown }\end{array}$ & $\begin{aligned} 338 & (58 \cdot 5 \%) \\
205 & (35 \cdot 5 \%) \\
31 & (5 \cdot 4 \%) \\
2 & (0 \cdot 3 \%) \\
2 & (0 \cdot 3 \%)\end{aligned}$ \\
\hline $\begin{array}{l}\text { Tumour diameter }(\mathrm{mm}) \\
\leqslant 2 \cdot 00 \\
2 \cdot 00-4 \cdot 99 \\
\geqslant 5 \cdot 00 \\
\text { Unknown }\end{array}$ & $\begin{aligned} 266(46 \cdot 0 \%) \\
152(26 \cdot 3 \%) \\
35(6 \cdot 1 \%) \\
125(21 \cdot 6 \%)\end{aligned}$ \\
\hline $\begin{array}{l}\text { Number of lymph nodes positive } \\
0 \\
1-3 \\
4-9 \\
\geqslant 10 \\
\text { Unknown - not done } \\
\text { Unknown - no data }\end{array}$ & $\begin{aligned} 210 & (36 \cdot 3 \%) \\
114 & (19 \cdot 7 \%) \\
31 & (5 \cdot 4 \%) \\
19 & (3 \cdot 3 \%) \\
198 & (34 \cdot 3 \%) \\
6 & (1 \cdot 0 \%)\end{aligned}$ \\
\hline $\begin{array}{l}\text { Oestrogen-receptor status } \\
\text { Positive } \\
\text { Negative } \\
\text { Unknown }\end{array}$ & $\begin{array}{r}99(17 \cdot 1 \%) \\
87(15 \cdot 1 \%) \\
392(67 \cdot 8 \%)\end{array}$ \\
\hline $\begin{array}{l}\text { Histopathological grade } \\
\text { I - well differentiated } \\
\text { II - moderately differentiated } \\
\text { III - poorly differentiated } \\
\text { Lobular } \\
\text { Unknown }\end{array}$ & $\begin{array}{c}31(5 \cdot 4 \%) \\
149(25 \cdot 8 \%) \\
167(28.9 \%) \\
40(6 \cdot 9 \%) \\
191(33 \cdot 0 \%) \\
\end{array}$ \\
\hline $\begin{array}{l}\text { Operation and radiotherapy } \\
\text { Mastectomy, no radiotherapy } \\
\text { Mastectomy and radiotherapy } \\
\text { Lumpectomy, no radiotherapy } \\
\text { Lumpectomy and radiotherapy } \\
\text { Unknown }\end{array}$ & $\begin{array}{c}45(7 \cdot 8 \%) \\
49(8 \cdot 5 \%) \\
8(1 \cdot 4 \%) \\
449(77 \cdot 7 \%) \\
27(4 \cdot 7 \%)\end{array}$ \\
\hline $\begin{array}{l}\text { Chemotherapy, endocrine therap } \\
\text { Yes } \\
\text { No } \\
\text { Unknown }\end{array}$ & $\begin{array}{c}461(79 \cdot 8 \%) \\
115(19.9 \%) \\
2(0.3 \%)\end{array}$ \\
\hline
\end{tabular}

Table 1: Demographic and clinical characteristics at enrolment $(n=578)$

\section{Methods}

\section{Participants}

Women with early-stage breast cancer (stages I and II) who presented consecutively at the Royal M arsden Hospital, London and Sutton, U K, were invited to participate in the study. Eligibility criteria for the cohort were: age between 18 and 75 years; ability to complete a questionnaire; awareness of their cancer diagnosis; no apparent serious intellectual impairment; and diagnosis 4-12 weeks before the inclusion date. All patients meeting the eligibility criteria were identified from hospital records and approached during their normal hospital outpatient visits, when they were asked if they would be willing to take part in a study assessing the emotional and psychological impact of cancer. Local research ethics committee approval was obtained before the start of the study. Of the patients surveyed, $658(95 \%)$ agreed to participate in the psychological assessment. Of these, 55 were not eligible because they had al ready relapsed between the point of identification for entry and the psychological assessment. 16 women were later confirmed as having non-invasive breast cancer and in nine women there was inadequate information to confirm whether the cancer was invasive. Therefore, the final cohort for the 5-year survival analyses consisted of 578 patients with confirmed invasive breast cancer.

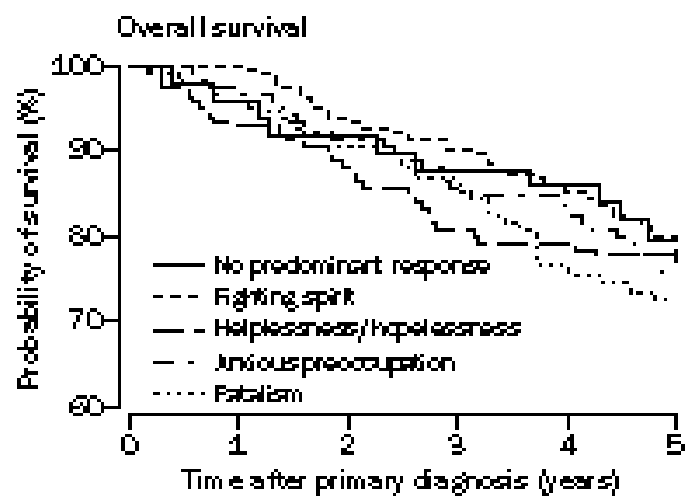

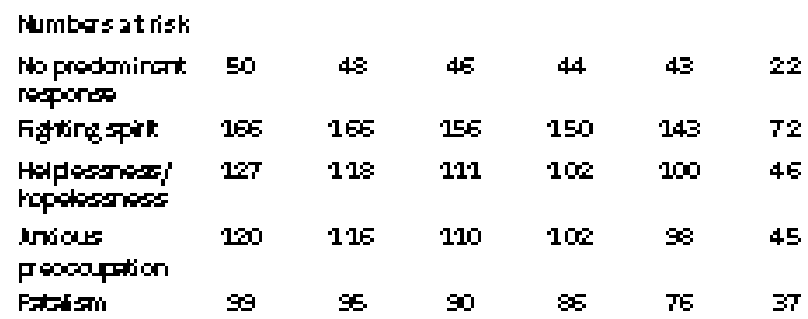

Evert-free survivol

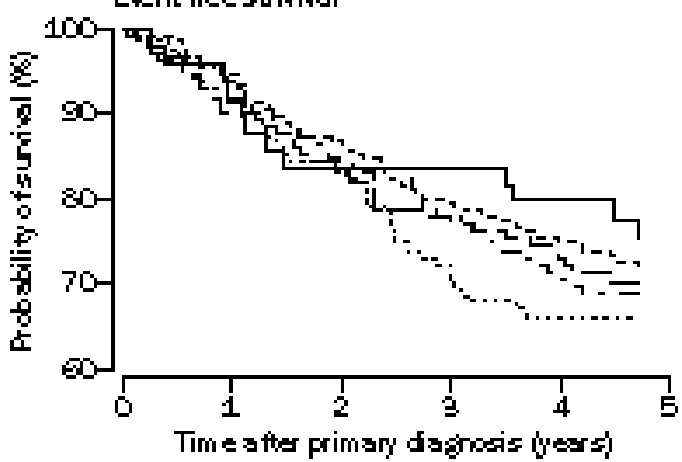

rumbarsat risk

\begin{tabular}{|c|c|c|c|c|c|}
\hline $\begin{array}{l}\text { 16 predanirant } \\
\text { respores }\end{array}$ & 50 & 46 & 42 & 42 & 40 \\
\hline 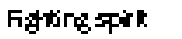 & 106 & 156 & 144 & 132 & 125 \\
\hline 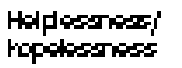 & 127 & 113 & 108 & 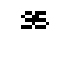 & 90 \\
\hline $\begin{array}{l}\text { irious } \\
\text { poosaption }\end{array}$ & 120 & 110 & 101 & 98 & 85 \\
\hline FAtনism & 99 & 98 & 82 & 69 & 64 \\
\hline
\end{tabular}

Figure 1: Overall and event-free survival according to predominant response on the MAC scale

\section{Procedure}

Patients were assessed by self-administered questionnaires selected for validity, reliability, and previous use in this population. Participants completed the study measures at 4-12 weeks after diagnosis and 1 year later. The patients were recruited into the study in the context of screening for eligibility for a psychological intervention study, and were unaware of the hypotheses being investigated in this follow-up study. This approach reduced any bias in the reporting of psychological response. The questionnaires were:

MAC scale ${ }^{12}-T$ his brief 40 -item questionnaire was developed to assess patients' reactions to having cancer in five dimensions: fighting spirit, helplessness or hopelessness, anxious preoccupation, fatalism, and avoidance (the latter two being previously labelled as stoic acceptance and denial ${ }^{13}$ ). Fighting spirit is characterised by a determination to fight the illness and adopt an optimistic attitude (eg, "I see my illness as a challenge"). Patients showing a response of helplessness or hopelessness may feel engulfed by knowledge of the diagnosis and have a wholly pessimistic attitude (eg, "I feel like 


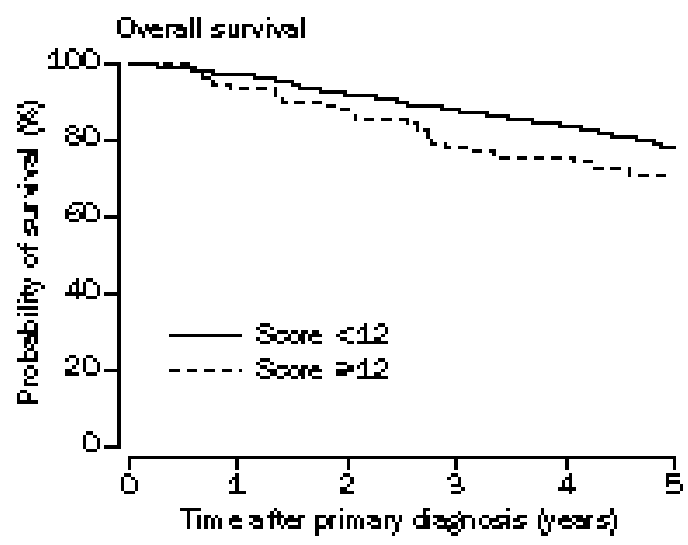

Numbers at risk

$\begin{array}{ccccccc}\operatorname{sog} 0 \times 12 & 455 & 473 & 448 & 427 & 405 & 194 \\ s 00012 & 91 & 85 & 50 & 71 & 69 & 35\end{array}$

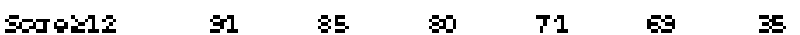
Event-fiee survivol

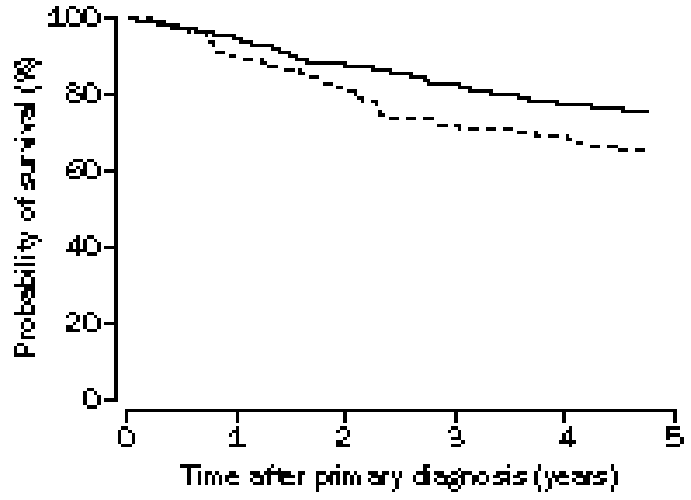

Numbors at risk

$\begin{array}{ccccccc}s \sigma r \% 412 & 4 \$ 5 & 453 & 415 & \$ 8 & 3 s 8 & 174 \\ s \sigma r \%=12 & \$ 1 & \$ 0 & 72 & 62 & 59 & 29\end{array}$

Figure 2: Overall and event-free survival according to score on MAC category 'helplessness and hopelessness'

giving up"). This measure, which has been independently validated, ${ }^{14,15}$ showed high concordance with the clinical interview assessment method used by $\mathrm{G}$ reer and colleagues. ${ }^{13} \mathrm{M}$ ental adjustment to cancer, as assessed by this measure, involves the tendency to cope with the stress of cancer in a particular way and has been found to be significantly associated with measures of depression and anxiety. ${ }^{16}$

CEC scale ${ }^{17}-T$ his scale assesses the extent to which patients suppress negative emotions; a focal variable of the suggested type $C$ cancer-prone personaility. The questionnaire assesses the tendency to respod to feelings of anxiety, sadness, and anger by suppressing or controlling reactions when these emotions are experienced.

Hospital anxiety and depression scale (HAD) $)^{18}-T$ his widely used screening tool assesses anxiety and depression as two dimensions and has been validated in cancer patients. ${ }^{19}$

$D$ ata were collected from medical records on initial disease stage, type of treatment, and disease outcome 5 years after study entry. M edical information was missing in some cases because it was not recorded in the medical notes. The most common reason for absence of data was that they had not been collected at the time of breast-cancer diagnosis.

\section{Statistical methods}

The MAC scale was analysed in two different ways. First, to replicate the analysis of Greer and colleagues, ${ }^{10}$ each patient was classified as having one predominant response from the categories of fighting spirit, helplessness or hopelessness, anxious preoccupation, and fatalism. To classify a patient's predominant response, each of the M AC subscale scores was converted to a z-score according to the mean and SD . E ach patient was then assigned to a group representing her predominant response according to the MAC subscale with the highest standardised score. Where no standardised score was greater than zero (ie, the sample mean), the patient was classified as having no predominant response. The avoidance subscale was not included in this categorisation because it consists of only one item from the MAC questionnaire, and calculation of a standardised score is not feasible.

Second, each of the individual MAC subscales was dichotomised with standard cut-off scores (according to the guidelines of the developers of the test) ${ }^{20}$ to define cases (ie, patients judged to be at high psychological risk on this assessment). The cut-off scores correspond to the value of the mean plus 1 SD, for each individual subscale, as defined in the M AC users manual. ${ }^{12}$ For the HAD scale, each of the subscale scores (anxiety and depression) was divided into three categories: 0-7 (non-case); 8-10 (borderline case); and 11 or more (case). ${ }^{18}$

Relapse data were only recorded if relapse occurred within 5 years of enrolment into the study, so all our analyses were truncated at 5 years, although mortality data were collected beyond 5 years of follow-up. K aplan-M eier survival methods were used to obtain estimates of survival and event-free survival at 5 years, and the log-rank test was used to test for significance between survival curves of the various categories of psychological response. Cox's proportional-hazards regression models were fitted to obtain the hazard ratios (together with $95 \% \mathrm{Cl}$ ) for the measures of psychological response, with adjustement for clinical factors that are associated with overall and event-free survival in breast cancer: histopathological grade, number of positive lymph nodes, tumour size, type of operation, whether the patient received chemotherapy or endocrine therapy, and oestrogen-receptor status.

The psychological measures were also assessed in regression analyses as covariates (ie, with the original uncategorised scores), but because the results were extremely similar to those obtained with the categorical data, only the latter results are presented. To use the updated psychological response data collected at 1 year of follow-up, regression models were fitted in exactly the same way for the initial analyses, but the MAC and HAD scales were fitted as time-dependent factors. We checked the assumptions of proportional hazards by plotting the cumulative hazard functions for each category of the psychological measures.

The significance of our findings must be interpreted with caution owing to the number of statistical tests done. All hypotheses relating to the associations between each individual psychological measure, and overall or event-free survival were stated a priori.

The Cox's proportional-hazards regression analyses of overall survival were repeated with all available data on follow-up and deaths (ie, data beyond 5 years) but the results were very similar to those obtained for 5-year overall survival and so only the latter results are presented.

\section{Results}

578 breast-cancer patients were enrolled into the study (table 1). The mean age of the women was 55 years (SD 10.6). Of the 415 women for whom social class could be defined, 282 (68\%) were in classes I to III-non manual. $64 \%$ were married.

The overall median follow-up was 4.93 years (IQR $4 \cdot 58-5 \cdot 18) .160(27 \cdot 7 \%)$ women relapsed and in these women the median time to relapse was 2.12 years (1.08-3.25). $133(23.0 \%)$ had died by 5 years of follow-up, $122(21 \cdot 1 \%)$ of breast cancer. In the remaining 11 women, cause of death could not be ascertained from the hospital, general practitioner, or cancer registry records. For the analyses of event-free survival, $173(29.9 \%)$ had died from breast cancer or relapsed by 5 years. Therefore, at 5 years $395(68.3 \%)$ patients were alive and without relapse, 50 $(8.7 \%)$ were alive with relapse, and $133(23.0 \%)$ had died. 


\begin{tabular}{|c|c|c|c|c|}
\hline & $\begin{array}{l}\text { Alive with no } \\
\text { recurrence } \\
\text { ( } n=395)\end{array}$ & $\begin{array}{l}\text { Alive with } \\
\text { recurrence } \\
(n=50)\end{array}$ & $\begin{array}{l}\text { Dead } \\
(n=133)\end{array}$ & $\begin{array}{l}\text { Total } \\
(n=578)\end{array}$ \\
\hline \multicolumn{5}{|l|}{ MAC predominant response } \\
\hline None & $37(74 \%)$ & $3(6 \%)$ & $10(20 \%)$ & 50 \\
\hline Fighting spirit & $117(70 \%)$ & $14(8 \%)$ & $35(21 \%)$ & 166 \\
\hline Helplessness/hopelessness & $82(65 \%)$ & $16(13 \%)$ & $29(23 \%)$ & 127 \\
\hline Anxious preoccupation & $81(68 \%)$ & $9(8 \%)$ & $30(25 \%)$ & 120 \\
\hline Fatalism & $64(65 \%)$ & $8(8 \%)$ & $27(27 \%)$ & 99 \\
\hline Unknown & $14(88 \%)$ & 0 & $2(13 \%)$ & 16 \\
\hline \multicolumn{5}{|l|}{ HADS anxiety } \\
\hline $0-7$ & $283(70 \%)$ & $38(9 \%)$ & $86(21 \%)$ & 407 \\
\hline $8-10$ & $67(66 \%)$ & $8(8 \%)$ & $27(27 \%)$ & 102 \\
\hline$\geqslant 11$ & $44(65 \%)$ & $4(6 \%)$ & $20(29 \%)$ & 68 \\
\hline Unknown & 1 & 0 & 0 & 1 \\
\hline \multicolumn{5}{|l|}{ HADS depression } \\
\hline $0-7$ & $370(68 \%)$ & $48(9 \%)$ & $123(23 \%)$ & 541 \\
\hline $8-10$ & $20(74 \%)$ & $2(7 \%)$ & $5(19 \%)$ & 27 \\
\hline$\geqslant 11$ & $5(50 \%)$ & 0 & $5(50 \%)$ & 10 \\
\hline
\end{tabular}

Percentages are row percentages.

Table 2: 5-year outcome according to baseline MAC predominant response scores and HAD scale scores

There were no significant effects of psychological response on overall or event-free survival. Comparisons that attempted to replicate previous findings ${ }^{10}$ showed no significant association between the predominant response in the M AC scale and overall $(p=0 \cdot 73)$ or event-free survival $(p=0.63)$, with exclusion of women with a missing response (data missing on the MAC sub-scales; figure 1, table 2). In analysis with dichotomised scores for each individual psychological response on the MAC scale, a helplessness or hopelessness score was associated with increased risk of death or relapse over the 5 years of follow-up, with the results for event-free survival reaching statistical significance (overall survival; $p=0.08$, and event-free survival $p<0.01$; figure 2 ). In regression analyses there was a significant effect of a high score on the M AC helplessness or hopelessness subscale on event-free survival $(p<0.01)$, which decreased slightly after adjustment for prognostic factors.

A high score on the depression subscale of the HAD scale was significantly associated with overall survival in regression analysis $(p<0.05)$, and the effect became stronger after adjustment for prognostic factors $(p<0.01$; table 3$)$. For event-free survival the effect of a high score on the depression subscale of the HAD scale was not significant (table 4).

Psychological assessments at 1 year of follow-up were available for 455 women, although there were varying amounts of missing data for some of the individual scores. The number of women who had the same category of M AC predominant response at 1 year as at baseline was 202 $(47 \cdot 3 \%)$ of 427 women with follow-up data. H owever, the proportion of women remaining in the same category (ie, above or below the cut-off point that defined a case) was much higher for the individual MAC and HAD scale scores, ranging from $77 \%$ for $M A C$ fighting spirit and $86 \%$ for helplessness or hopelessness to $96 \%$ for depression in the HAD scale $(p<0.001$ for all $\kappa$ statistics).

Because the baseline and follow-up psychological data were all highly correlated, we would not expect the results of a survival analysis that takes into account the timedependency of the data, to produce results very different from the analyses that only used enrolment data. H owever, such models were fitted with Cox's proportional-hazards regression with time-dependent factors for the updated $M A C$ and HAD scale scores to verify this expectation. With adjustment for the same set of clinical prognostic factors as in the previous analyses, the following minor differences from the previous analysis of baseline psychological data were observed. For overall survival, the increased risk of death during follow-up for the HAD scale category of depression remained significant (adjusted hazard ratio 4.04 [95\% Cl 1.54-10.64] for a score of $\geqslant 11$ on HAD scale

\begin{tabular}{|c|c|c|c|}
\hline & Deaths/ total (death rate) & Crude hazard ratio $(95 \% \mathrm{Cl})$ & Adjusted hazard ratio $(95 \% \mathrm{Cl})^{*}$ \\
\hline \multicolumn{4}{|c|}{ MAC scale predominant responses } \\
\hline None & $10 / 50(20 \%)$ & 1.00 & 1.00 \\
\hline Fighting spirit & $35 / 166(21 \%)$ & $1.03(0.51-2.07)$ & $0.86(0.42-1.76)$ \\
\hline Helplessness/hopelessness & $29 / 127(23 \%)$ & $1.21(0.59-2 \cdot 49)$ & $0.95(0.46-1.98)$ \\
\hline Anxious preoccupation & $30 / 120(25 \%)$ & $1.28(0.62-2.61)$ & $1.04(0.50-2 \cdot 17)$ \\
\hline Fatalism & $27 / 99(27 \%)$ & $1.41(0.68-2.92)$ & $1.02(0.49-2 \cdot 15)$ \\
\hline Unknown & $2 / 16(13 \%)$ & $0.58(0.13-2.67)$ & $0.37(0.08-1.71)$ \\
\hline \multicolumn{4}{|l|}{ MAC-fighting spirit } \\
\hline$>47$ & $94 / 412(23 \%)$ & 1.00 & 1.00 \\
\hline$\leqslant 47$ & $39 / 162(24 \%)$ & $1.10(0.76-1.60)$ & $1.11(0.76-1.62)$ \\
\hline \multicolumn{4}{|c|}{ MAC-helplessness/ hopelessness } \\
\hline$<12$ & $106 / 486(22 \%)$ & 1.00 & 1.00 \\
\hline$\geqslant 12$ & $27 / 91(30 \%)$ & $1.45(0.95-2.22)$ & $1.30(0.84-2.00)$ \\
\hline \multicolumn{4}{|l|}{ MAC-anxious preoccupation } \\
\hline$<26$ & $113 / 507(22 \%)$ & 1.00 & 1.00 \\
\hline$\geqslant 26$ & $19 / 69(28 \%)$ & $1 \cdot 29(0 \cdot 80-2 \cdot 11)$ & $1.21(0.73-2.00)$ \\
\hline \multicolumn{4}{|l|}{ MAC-fatalism } \\
\hline$<23$ & $116 / 512(23 \%)$ & 1.00 & 1.00 \\
\hline$\geqslant 23$ & $16 / 60(27 \%)$ & $1.19(0 \cdot 70-2 \cdot 01)$ & $1.04(0.61-1.79)$ \\
\hline \multicolumn{4}{|l|}{ MAC-avoidance } \\
\hline$<4$ & $123 / 544(23 \%)$ & 1.00 & 1.00 \\
\hline 4 & $8 / 29(28 \%)$ & $1.23(0.60-2.52)$ & $1.53(0.72-3.28)$ \\
\hline \multicolumn{4}{|l|}{ HADS-anxiety } \\
\hline $0-7$ & $86 / 407(21 \%)$ & 1.00 & 1.00 \\
\hline $8-10$ & $27 / 102(27 \%)$ & $1.29(0.83-1.98)$ & $1.35(0.86-2 \cdot 11)$ \\
\hline$\geqslant 11$ & $20 / 68(29 \%)$ & $1.47(0.91-2.40)$ & $1.54(0.93-2.56)$ \\
\hline \multicolumn{4}{|l|}{ HADS-depression } \\
\hline $0-7$ & $123 / 541(23 \%)$ & 1.00 & 1.00 \\
\hline $8-10$ & $5 / 27(19 \%)$ & $0.80(0.33-1.95)$ & $0.74(0.30-1.84)$ \\
\hline$\geqslant 11$ & $5 / 10(50 \%)$ & $2.52(1.03-6.16) \dagger$ & $3.59(1.39-9.24) \ddagger$ \\
\hline
\end{tabular}

*Adjusted for histopathological grade, number of positive lymph nodes, tumour size, type of operation received, chemotherapy and/ or endocrine therapy, oestrogen-receptor status, and age. $\dagger p<0.05 ; \neq p<0.01$.

Table 3: Results of Cox's proportional-hazards regression analysis for baseline psychological measures and overall survival at 5 years 


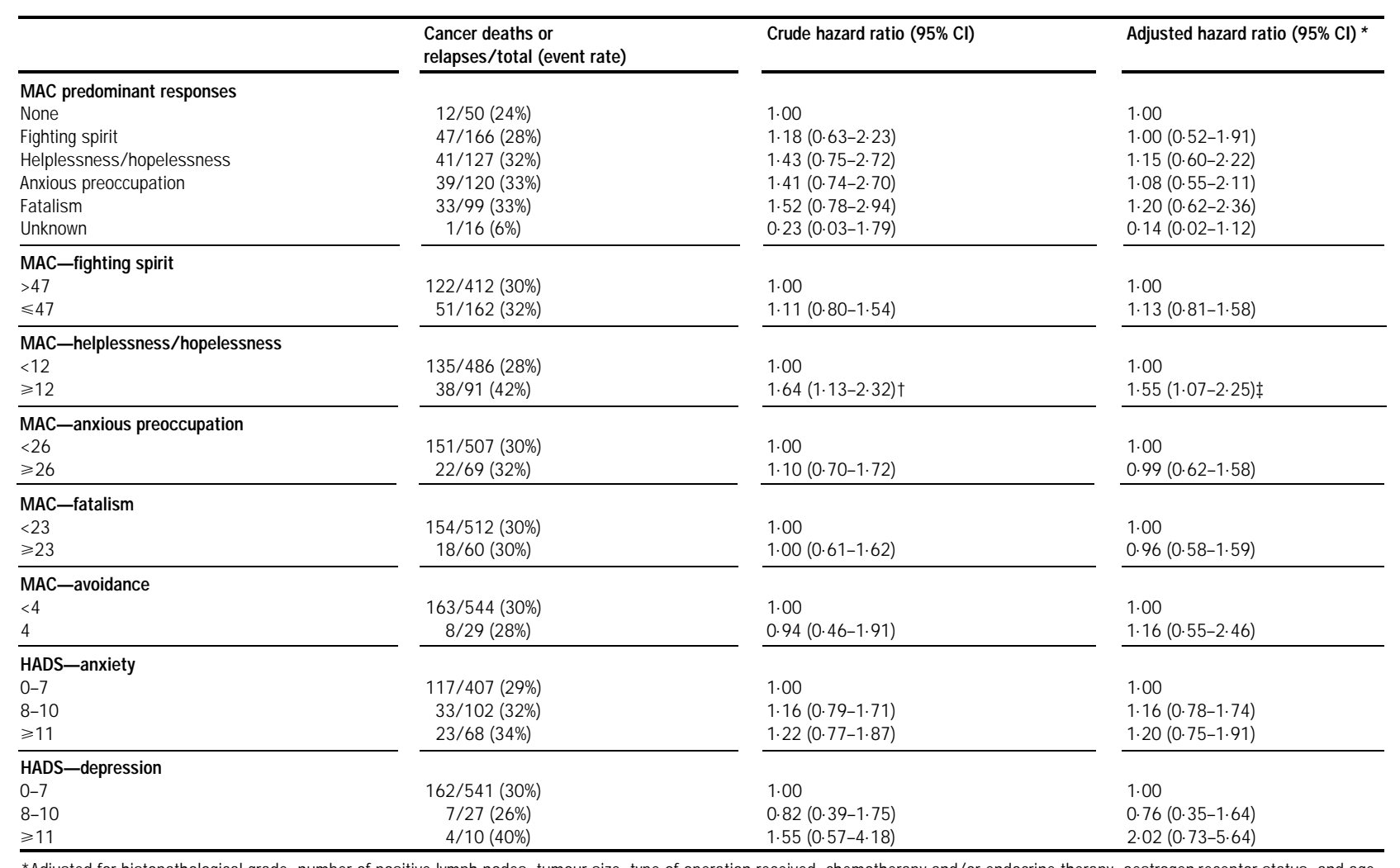

*Adjusted for histopathological grade, number of positive lymph nodes, tumour size, type of operation received, chemotherapy and/ or endocrine therapy, oestrogen-receptor status, and age. $\dagger p<0.05 ; \neq p<0.01$

Table 4: Results of Cox's proportional-hazards regression analysis for baseline psychological measures and event-free survival at 5 years

depression). For event-free survival the effect of MAC helplessness or hopelessness was reduced from before $(1.35$ [0.91-2.00]), and was no longer significant. The CEC scale scores showed no significant associations with overall or event-free survival (data not shown).

\section{Discussion}

In this large population-based cohort study, the psychological data are largely free from measurement bias because the women were approached in the context of screening for an intervention trial ${ }^{21}$ rather than an observational study of the association between their psychological response and survival, and so they were unaware of the study hypothesis. Only one patient was lost to follow-up after 5 years. Several questionnaires were used in the data collection, and the psychological assessments were repeated at 1 year of follow-up. We attempted to replicate the results reported by Greer and colleagues ${ }^{10}$ but could find no survival difference when comparing one type of psychological response with another. There was no effect on survival of high versus low M AC scores for the category of fighting spi rit.

There was no significant effect of scores for emotional control on survival. Although suppression of negative emotions has been suggested as a focal characteristic of the type $C$ cancer-prone personality, we could find no evidence that this tendency has any effect on survival in this group.

There was a significant association between a helplessness or hopelessness response and relapse-free survival at 5 years. With control for known prognostic factors, this effect was reduced but remained significant. Patients who had a high score on the helpless measure at baseline were more likely to have relapsed or died during the 5 years. When we examined this effect with psychological scores assessed 1 year later, the association of the helpless response with relapse-free survival remained but was no longer significant, perhaps because some women's scores changed from the high to low helpless category (compared with baseline) thereby reducing the numbers available for analysis. The results for the HAD scale category of depression indicated increased risk of death by 5 years in women with high initial scores and, after adjustment for known clinical prognostic factors, this association was strengthened. The number of women scoring in the clinically depressed range at baseline (ie, defined as a score of $\geqslant 11$ ) was small $(2 \%)$.

The idea that an attitude of fighting spirit, in relation to cancer, improves overall length of survival has been embraced with enthusiasm, especially by practitioners of alternative therapies. Fighting spirit (as assessed here on the MAC scale) was not associated with improved survival in this study; such claims should be far more cautious and circumspect. Our findings suggest that women can be relieved of the burden of guilt that occurs when they find it difficult to maintain a fighting spirit. Further research is needed to clarify whether positive psychological responses not assessed by the M AC scale could have a role in breastcancer prognosis.

Our results raise several questions. The observed association between helplessness or hopefulness and depression, as early responses to breast cancer, with subsequent overall prognosis requires explanation. A few significant results could have occurred purely by chance because a large number of tests have been done. H ence we have presented for all the hazard-ratio estimates rather than showing exact $p$ values, because $\mathrm{CI}$ s are more interpretable where multiple significance testing has occurred. The number of women scoring in the depressed range $(\geqslant 11)$ for 
the H AD scale was small (2\%). This small sample, and the wide $\mathrm{CIs}$, suggest that more evidence is needed before we can conclude that depression has a significant effect on survival. Replication of this study with a larger sample of depressed patients would be worthwhile.

The effect of helplessness or hopelessness, although modest, is more robust because a large number of patients were in this category and the Cls were narrower. We suggest several explanations for the association between the helplessness or hopelessness response and event-free survival. First, psychological response may influence biological response via immune function. H owever, the link between immunosuppression and breast-cancer progression remains unproven. Second, the direct effect of psychological response on stress hormones (eg, prolactin) which might have an effect on disease processes, could be investigated. Third, psychological response may moderate important aspects of social functioning. Patients who hold a helpless attitude may be less proactive in obtaining the amount of health care needed to obtain the maximum possible survival and this effect needs to be investigated. Finally, the biology of the tumour may have caused the psychological response assessed at baseline, although we know of no evidence that supports this explanation. F urther studies should investigate possible explanatory mechanisms.

Whatever the explanatory mechanisms, Greer and colleagues have already shown in a randomised trial the helplessness or hopelessness response can be improved by the use of cognitive-behavioural therapy. ${ }^{21} \mathrm{~T}$ his type of brief psychological therapy can be used to bring improvements in the degree of helplessness experienced by some patients and possibly in length of survival, although we have not tested the latter hypothesis.

These data indicate that a helpless response along with known clinical prognostic factors has a modest association with poorer survival. Our results need to be put in context. Although this study is large compared with previous studies of psychological response and survival, the trial is smaller than most trials of adjuvant therapy, most of which have at least 1000 patients. H ence, with 578 patients in this study, the actual effect of psychological response on survival would have to be greater than the effect of adjuvant therapy (eg, about $10 \%$ absolute improvement in 10-year survival for tamoxifen $^{22}$ to show a highly significant result). The small number of patients scoring in the HAD scale clinical range also limits the analysis, and although a significant effect was found, a conclusive result will require replication in a larger sample of depressed patients.

Although the association between a response of helplessness or hopelessness and disease outcome observed in this study is modest, the association is not trivial. For clinicians treating breast-cancer patients, the results reinforce the need to detect a response of helplessness or hopelessness and serious depression, and treat these responses vigorously to help women improve quality of life and optimise length of survival.

The data reported here will help clarify the question of whether psychological response has an effect on survival. The negative finding in relation to the fighting spirit response is important and the association between helplessness and survival reinforces the need to ensure there is adequate provision of psychological care within oncology aimed at encouraging patients to feel less helpless and hopeless.

\section{Contributors}

M W atson was responsible for the design and conduct of the study, D avidson was responsible for management, and I $\mathrm{H}$ aviland and J Bliss for statistical analysis. S Greer assisted in the design of the study and the development of the measures of adjustment to cancer. All investigators contributed to the writing of the study report.

\section{Acknowledgments}

We thank S Anderson, J Baruch, G Chesney, C Gorman, B Gusterson, M Law, A M ason, B Robertson, L Rowden, H Saunders, R T unmore for their assistance; and the Cancer Research Campaign (C RC Project CP1008) for funding the study. We thank the late T im M CE Iwain who encouraged us to investigate these issues; the late T ereza G ladwell, our data manager for 3 years of the study; and the anonymous participating patients who gave their time so willingly.

\section{References}

1 Weisman AD, Worden JW. Coping and vulnerability in cancer patients. Boston: M assachusetts G eneral H ospital, 1977.

2 Levy SM, Lee J, Bagley C, Lippman M. Survival hazards analysis in first recurrent breast cancer patients: seven year follow-up. P sychosom $M$ ed 1988; 50: 520-28.

3 H olland IC, Korzun AH, T ross S, C ella DF, N orton L, Wood W. Psychosocial factors and disease free survival in stage II breast carcinoma. Proc A m Soc C lin Oncol 1986; 5: 237 (abstr).

4 Jamieson RN, Burish T G, Wallston KA. Psychogenic factors in predicting survival of breast cancer patients. J Clin O ncol 1987; 5: 768-72.

5 Buddeberg $C$, Wolf $C$, Sieber $M$, et al. Coping strategies and course of disease of breast cancer patients. Psychother and P sychosom 1991; 55: 151-57.

$6 \mathrm{M}$ orris T. A 'T ype C' for $\mathrm{C}$ ancer?: low trait anxiety in the pathogeneis of cancer. Cancer D etect Prev 1980; 3: 102.

7 W atson M, Pettingale K W, G reer S. Emotional control and autonomic arousal in breast cancer patient. J Psychosom R es 1984; 28: 467-74.

8 G oldstein D A, Antoni M H. The distibution of repressive coping styles among non-metastatic and metastastatic breast cancer patients as compared to non-cancer patients. P sychol $\mathrm{H}$ ealth 1989; 3: 245-58.

9 Copper CL, Faragher EB. Psychosocial stress and breast cancer: the inter-relationship between stress events, coping strategies and personality. Psychol M ed 1993; 23: 653-62.

$10 \mathrm{G}$ reer $\mathrm{S}, \mathrm{M}$ orris T, Pettingale KW. Psychological response to breast cancer; effect on outcome. L ancet 1979; ii: 785-87.

11 Pettingale K W, M orris T, G reer S, Haybittle J. mental attitudes to cancer: an additional prognostic factor. $L$ ancet 1985; i: 750.

12 W atson M, Greer S, Y oung J, I nayat Q, Burgess C, Robertson C. D evelopment of an questionnaire measure of adjustment to cancer: the M AC scale. Psychol M ed 1988; 18: 203-09.

13 Greer S, M oorey S, Watson M. Patients' adjustment to cancer: the $M$ ental Adjustment to $C$ ancer ( $M A C$ ) scale vs clinical ratings. J Pschosom Res 1989; 33: 373-77.

14 Schnoll RA, H arlow LL, B randt U, Stolback LL. U sing two factor structures of the $M$ ental Adjustment to $C$ ancer ( $M A C$ ) Scale for assessing adaptation to breast cancer. P sychol O ncol 1998; 7: 424-35.

15 N ordin K, Berglund G, T erje I, G limelius B. The M ental Adjustment to $C$ ancer Scale: a psychometric analysis and the concept of coping. Psychol Oncol 1999; 8: 250-59.

16 Watson M , Greer S, R owden L, et al. R elationships between emotional control, adjustment to cancer and depression and anxiety in breast cancer patients. Psychol M ed 1992; 21: 51-57.

17 Watson M, Greer S. D evelopment of a questionnaire measure of emotional control. J Psychosom R es 1983; 27: 299-305.

18 Zigmond AS, Snaith RP. T he H ospital Anxiety and D epression Scale. A cta Psychiatr Scand 1983; 67: 361-70.

19 M oorey S, G reer S, W atson M , et al. T he factor structure and factor stability of the $\mathrm{H}$ ospital Anxiety and D epression Scale in patients with cancer. BrJ Psychiatry 1990; 158: 255-59.

20 Watson M , G reer S, Bliss JM . M ental Adjustment to $\mathrm{C}$ ancer (M AC) scale users manual. Sutton: R oyal M arsden $\mathrm{H}$ ospital, 1989.

21 G reer S, M oorey S, Barach JD R, et al. Adjuvant psychological therapy for patients with cancer: a prospective randomised trial. B M J 1992; 304: 675-80.

22 E arly Breast C ancer T railist's C ollaborative G roup. Tamoxifen for early breast cancer: an overview of the randomised trials. Lancet 1998; 351: 1451-67. 